\title{
Zero-Shear Viscosity of Aqueous Solutions of Sodium Hyarulonate: Analysis as Semiflexible Polymer Solutions
}

\author{
Takahiro SATO $^{* 1}$, Shin-ichi YAMAMOTO*2, Toshikazu TAKIGAWA ${ }^{* 2}$, and Toshiro MASUdA ${ }^{* 2}$ \\ ${ }^{* 1}$ Department of Macromolecular Science, Osaka University, Toyonaka, Osaka 560-0043, Japan \\ *2 Department of Material Chemistry, Kyoto University, Sakyo-ku, Kyoto 606-8501, Japan
}

\begin{abstract}
Zero-shear viscosities $\eta_{0}$ of aqueous solutions of sodium hyarulonate were compared with the fuzzy-cylinder model theory, a typical theory for semiflexible polymer solutions. Taking into account electrostatic contributions to the chainstiffness and excluded-volume effect, the theory quantitatively describes the concentration dependence of $\eta_{0}$ at molecular weights lower than $10^{6}$. On the other hand, the theory predicts too strong concentration dependence of $\eta_{0}$ at molecular weights higher than $10^{6}$ at high polymer concentrations. These results indicate that the flexible-chain dynamics (e.g., reptation motion), neglected in the fuzzy-cylinder model theory, are not important in solution viscosity for lower molecular weight sodium hyarulonate, but become important with increasing the molecular weight.

Key Words : Sodium hyarulonate / Zero-shear viscosity / Semiflexible polymer / Fuzzy-cylinder model theory
\end{abstract}

\section{ヒアルロン酸ナトリウム水溶液のゼロずり粘度：半屈曲性高分子 溶液としての解析}

\author{
佐藤 尚弘 ${ }^{* 1}$, 山本 真一 ${ }^{* 2}$, 瀧川 敏算 ${ }^{* 2}$, 升田 利史郎 ${ }^{* 2}$
}

(原稿受理 : 2001年6月 11日)

1. 緒言

ヒアルロン酸は生体内で関節の潤滑など、重要な生理作用 を有する電解質多糖で, 医薬や化粧品などへの応用か期待さ れている. ${ }^{1)}$ このような重要性のために, 兴の水溶液のレオ ロジ一的性質には多くの関心か槣せられており，これまでに 数多くのレオロジー的研究がなされている. ${ }^{1.2)}$

水溶液中でのヒアルロン酸の持続長 $q$ は, イオン強度が十 分高いときには, $4 \mathrm{~nm}$ 程度で ${ }^{3 \sim 5)}$, 典型的な半屈曲性高分子, たとえばポリイソシアナート誘導体 $(q \cong 20 \sim 40 \mathrm{~nm})$ やセル ロース誘導体 $\left.(q \cong 10 \mathrm{~nm})^{\circ}\right)$, と比較すると高分子鎖の剛直性 は低いが, 典型的な屈曲性高分子鎖 $(q \cong 1 \mathrm{~nm})^{7)}$ より剛直で ある.さらに,一般に高分子電解質の場合, 水溶液中のイオン 強度を減少させていくと, 分子内の静電反発力によって高分 子鎖の剛直性が増大することが知られている.ヒアルロン酸

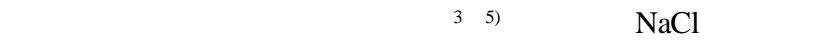
$\left(25^{\circ} \mathrm{C}\right)$ での分子形態力詳細に調べられており，q值はTable I に示すようにイオン強度Iの減少にともなって増大する.イオ ン強度が $0.01 \mathrm{M}$ 程度以下になると, ヒアルロン酸ナトリウム の $q$ は典型的な半屈曲性高分子の兰れと同程度となっている. また同時に, 高分子電解質分子内の静電相互作用は鎖に

${ }^{* 1}$ 大阪大学大学院理学研究科

T 560-0043 大阪府豊中市待兼山町 1-1

"2 京都大学大学院工学研究科

₹ 606-8501 京都府京都市左京区吉田本町
Table I Persistence length $q$ and the excluded-volume strength $B$ of sodium hyarulonate in aqueous sodium chloride $(\mathrm{NaCl})$ at 25 ${ }^{\circ} \mathrm{C}$, as functions of the ionic strength $I$ (Tsutsumi and Norisuye $^{5)}$ ).

\begin{tabular}{ccc}
\hline$I / \mathrm{M}$ & $q / \mathrm{nm}$ & $B / \mathrm{nm}$ \\
\hline 0.005 & 9.7 & 19 \\
0.0067 & 8.5 & 17 \\
0.01 & 7.4 & 13 \\
0.02 & 6.0 & 9.0 \\
0.05 & 5.0 & 7.0 \\
0.1 & 4.8 & 4.8 \\
0.2 & 4.2 & 4.0 \\
0.5 & 4.1 & 2.8 \\
1 & 4.0 & 2.3 \\
2.5 & 4.0 & 1.6 \\
\hline
\end{tabular}

沿って遠く離れたモノマー単位間にも働き，これは分子内排 除体積効果の増大をもたらす．Table Iには，ヒアルロン酸ナ トリウムの排除体積強度パラメータBのイオン強度依存性も 同時に示してある.

以上のように , ヒアルロン酸は水溶液中で典型的な屈曲性 高分子とは異なった分子形態を有しており，水溶液のレオロ ジ一的性質にも，鎖の剛直性（および強い排除体積効果）を 考慮する必要があると考えられる.実際,Fouissacら²)はヒアル ロン酸水溶液のゼロずり粘度の分子量依存性が通常の屈曲 
性高分子の濃厚溶液系よりも強いことを見い出し, これがヒ アルロン酸鎖の岡直性に依るとしている.しかしながら, 彼等 はヒアルロン酸濃厚水溶液のレオロジー的性質における鎖 の剛直性の効果を定量的には議論していない.

光こで本研究では, この系を半屈曲性高分子溶液と見な し, 最近行われたヒアルロン酸ナトリウム水溶液に対するゼ ロずり粘度の実験結果を, 半屈曲性高分子溶液に対する代表 的な理論であるファジー円筒モデルに基づく理論と比較し た.この理論は, これまでの研究により, 種々の剛直・半屈曲 性高分子溶液のゼロずり粘度をほぼ定量的に記述できるこ とが知られており ${ }^{6,8)}$, 以下ではヒアルロン酸水溶液系への同 理論の適用性について吟味し，この系のレオロジー的性質へ の高分子鎖の剛直性の効果を定量的に議論する.

\section{2. ファジー円筒モデル理論}

この理論の詳細については, 文献6，8にすでに述べられて いる.ここでは同理論を高分子電解質溶液に適用する際の注 意点を中心に述べる.この理論では, 溶液中の各高分子鎖を， 分子形態に関して平均化して得られる円筒対称のセグメン 卜分布 (ファジー円筒モデル) で置き換え, 高分子の全体運 動について議論する.各高分子鎖の内部運動については、陽に は議論しない.

ファジー円筒モデルの有効な長さ $L_{\mathrm{e}}$ と有効な太さ $d_{\mathrm{e}}$ は次式 で与えられるとする :

$$
L_{\mathrm{e}} \equiv\left\langle R^{2}\right\rangle^{1 / 2}, d_{\mathrm{e}} \equiv\left(\left\langle H^{2}\right\rangle+d^{2}\right)^{1 / 2}
$$

ここで， $\left\langle R^{2}\right\rangle$ と $\left\langle H^{2}\right\rangle$ は光れ光れ高分子鎖の自乗平均両末端 間距離および末端間軸と鎖の中点間の自乗平均距離を表わ し, $d$ は高分子鎖の実直径を表わす.平均量 $\left\langle R^{2}\right\rangle$ と $\left\langle H^{2}\right\rangle$ は, 高分子鎖の持続長 $q$ と全長 $L$ (あるいは $N \equiv L / 2 q$ で定義される Kuhnの統計セグメント数)，および排除体積強度パラメータ $B$ を用いて、次式より計算できる.

$$
\begin{aligned}
& \left\langle R^{2}\right\rangle=\alpha_{\mathrm{R}}^{2} \cdot(2 q)^{2}\left[N-\frac{1}{2}\left(1-\mathrm{e}^{-2 N}\right)\right] \\
& \left\langle H^{2}\right\rangle=p_{\mathrm{e}}{ }^{-2}\left\langle R^{2}\right\rangle
\end{aligned}
$$

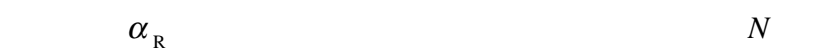
びBの関数であり ${ }^{9)} p_{\mathrm{e}}$ は高分子鎖の有効軸比を表わし,Nの関 数として与えられている ${ }^{6}\left(p_{\mathrm{e}}\right.$ に対する排除体積効果は考えな (). 高分子電解質の場合, $q$ と $B$ はイオン強度Iによって変化 し かつ高分子電解質自身が溶液のIに寄与するので $L_{\mathrm{e}}$ と $d_{\mathrm{e}}$ は 高分子電解質の濃度に依存することに注意する必要がある.

高分子の質量濃度が $c$ である溶液のゼロずり粘度 $\eta_{0}$ は次式 で与えられる.

$$
\frac{\eta_{0}}{\eta^{(\mathrm{S})}}=1+[\eta] c\left(1+k_{\mathrm{HI}}^{\prime}[\eta] c\right)\left[1+\frac{3}{4} \gamma \chi^{2}\left(\frac{\hat{D}_{\mathrm{r} 0}}{D_{\mathrm{r}}}-1\right)\right]
$$

ここで, $\eta^{(\mathrm{S})}$ は溶媒の粘性係数 , $[\eta]$ は固有粘度 , $\gamma$ と $\chi$ は計算 可能な゙流体力学的パラメータ, 乥して $k_{\mathrm{H}}^{\prime}$ は高分子間の流体力 学的相互作用の強さを表す係数である.また $D_{\mathrm{r}}$ は溶液中での
ファジー円筒の回転拡散係数, $\hat{D}_{\mathrm{r} 0}$ は高分子間のからみ合い 相互作用がないと仮定したときの $D_{\mathrm{r}}$ を表わす.もしも，高分子 鎖の形態が产の濃度とともに変化するならば , 式(4)中の $[\eta]$ には無限希釈状態での值ではなく，各濃度における高分子鎖 の形態に対応した (仮想的な) 值を用いる必要がある.有限濃 度での $[\eta]$ は, $L, q$, およびBの值を用いて , 山川ら"9 のみみ ず鎖に対する固有粘度の理論から計算することができる.

からみ合い効果を受けたファジー円筒の $D_{\mathrm{r}}$ は , 次式より計 算される.

$$
\frac{D_{\mathrm{r}}}{\hat{D}_{\mathrm{r} 0}^{\mathrm{r}}}=\left[1+\frac{L_{\mathrm{e}}{ }^{4}}{90 L} c^{\prime} f_{\mathrm{r}}\left(d_{\mathrm{e}} / L_{\mathrm{e}}\right)\left(\frac{F_{\| 0} \hat{D}_{\| 0}}{F_{\mathrm{r} 0} D_{\|}}\right)^{1 / 2}\right]^{-2}
$$

ただし, $c^{\prime}$ はファジー円筒の数濃度, $f_{\mathrm{r}}$ は $d_{\mathrm{e}} / L_{\mathrm{e}}$ の既知関数,$F_{\| 0}$ と $F_{\mathrm{r} 0}$ は計算可能な流体力学的パラメータ, 光して $D_{\|} / \hat{D}_{\| 0}$ は分 子間の衝突によるファジー円筒の縦方向の並進拡散の遅延 化を表わす因子で, 空孔理論に基づき次式より計算される.

$$
D_{\|} / \hat{D}_{\| 0}=\exp \left(-V_{\mathrm{ex}}{ }^{*} c^{\prime}\right)
$$

式中 , $V_{\mathrm{ex}}{ }^{*}$ は縦方向の拡散が起こるために必要な臨界空孔と障 害ファジー円筒との相互排除体積で , 臨界空孔とファジー円 筒との相似比 $\lambda *$ が与えられれば計算できる.これまでの研究 より, $\lambda^{*} に 0.03 〜 0.12 の$ 值を選ぶと実験と理論が良く一致す ることが知られている. ${ }^{6,8}$

粘度式(4)を濃度展開すると, $c$ 2次の係数より Huggins 係 数 $k^{\prime}$ が得られる.非電解質高分子の場合には, この $k^{\prime}$ の理論式 と実測の $k^{\prime}$ を比較することにより,式(4)中の $k_{\mathrm{H}}^{\prime}$ を求めること ができる.これに対して，イオン強度の低い高分子電解質溶液 の場合には，希薄領域で粘度の濃度依存性に異常性か現れ， $[\eta] お よ ひ ゙ k^{\prime} か$ 実測困難となる. (また，いわゆる電気粘性効果 に起因する項が新たに $k^{\prime} に$ 加わり， $k_{\mathrm{HI}}^{\prime}$ の項を抽出することが 難しい.)

高分子間の流体力学的相互作用は, 溶液のイオン強度には 直接的には光れほど依存しないと考えられる.弚こで,イオン 強度が十分高く, 高分子間の静電相互作用がほぼ完全に遮蔽 されている溶液について, 非電解質高分子と同じ方法で $k_{\mathrm{HI}}^{\prime}$ を 求め, 弚の值を兴のままイオン強度の低い溶液にも用いるこ とにする.

\section{3. 実験および測定試料の特性化}

レオロジー測定には, 電気化学工業社より提供されたヒア ルロン酸ナトリウム試料 (DHAS1) およびそれを窒素雰囲気 下 $70^{\circ} \mathrm{C}$ で $67 \mathrm{~h} \sim 490 \mathrm{~h}$ 熱処理し，分子量を低下させた 3 試料 (DHAS2, DHAS3, DHAS4) を用いた.各試料の0.2 M NaCl水溶

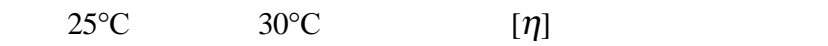
見積もつた粘度平均分子量 $M_{\mathrm{v}}$ を Table II に掲げる.ただし， DHAS1 とDHAS2の粘度測定には，4球蛇管式低ずり速度毛細 管粘度計を用いてゼロずり速度での $[\eta]$ を求め, $M_{\mathrm{v}}$ の見積も りには $\left.25^{\circ} \mathrm{Cにおける} \eta\right]$ と分子量の関係式5)を用いた。

各試料を純水に溶かし，質量濃度 $c$ が $1 \times 10^{-4}$ から $5 \times 10^{-2}$ $\mathrm{g} / \mathrm{cm}^{3}$ までの溶液を調製し, 温度 $35^{\circ} \mathrm{C}$ で動的粘弾性測定を行っ 
Table II Molecular characteristics of sodium hyarulonate samples used for viscometry.

\begin{tabular}{ccccc}
\hline sample & DHAS1 & DHAS2 & DHAS3 & DHAS4 \\
\hline$[\eta] / \mathrm{cm}^{3} \mathrm{~g}^{-1 \mathrm{a}}$ & 3680 & 2260 & 1570 & 970 \\
$M_{\mathrm{v}} / 10^{6 \mathrm{~b}}$ & 2.35 & 1.19 & 0.76 & 0.44 \\
$L / \mathrm{nm}^{\mathrm{c}}$ & 5900 & 3000 & 1900 & 1100 \\
$N\left(0.002 \mathrm{~g} / \mathrm{cm}^{3}\right)^{\mathrm{d}}$ & 300 & 150 & 98 & 57 \\
$N\left(0.005 \mathrm{~g} / \mathrm{cm}^{3}\right)^{\mathrm{d}}$ & 430 & 220 & 140 & 80 \\
$N\left(0.01 \mathrm{~g} / \mathrm{cm}^{3}\right)^{\mathrm{d}}$ & 520 & 260 & 170 & 96 \\
$N\left(0.02 \mathrm{~g} / \mathrm{cm}^{3}\right)^{\mathrm{d}}$ & 590 & 300 & 190 & 110 \\
$N\left(0.05 \mathrm{~g} / \mathrm{cm}^{3}\right)^{\mathrm{d}}$ & 660 & 330 & 210 & 120 \\
\hline
\end{tabular}

a Intrinsic viscosity in $0.2 \mathrm{M}$ aqueous $\mathrm{NaCl}$ at $25{ }^{\circ} \mathrm{C}$ (for DHAS1 and DHAS2) or $30{ }^{\circ} \mathrm{C}$ (for DHAS3 and DHAS4)

$\mathrm{b}$ Viscosity -average molecular weight determined from the relation between $[\eta]$ and molecular weight obtained by Tsutsumi and Norisuye ${ }^{5}$.

${ }^{c}$ Chain contour length estimated with the molar mass per unit contour length $M_{\mathrm{L}}=400$ $\mathrm{nm}^{-1}$.

d Number of Kuhn's statistical segments at the polymer concentration indicated in the parentheses, estimated from $q$ listed in Table 1 and eq (7).

た.高濃度溶液の測定には, ReoLogica Instrument社製DAR100 を，低濃度溶液についてはVilastic Science社製キャピラリー型 レオメータVilastic3 を使用した.測定角周波数 $\omega$ の範囲は $10^{-2}$ から $10^{2} \mathrm{~s}^{-1}$ までで, ゼロずり粘度 $\eta_{0}$ は損失弾性率を $\omega て ゙$ 割つ た量をゼロ周波数に外挿して求めた. ${ }^{10)}$

ヒアルロン酸ナトリウムの単位経路長当りの分子量 $M_{\mathrm{L}}$ は， イオン強度に依らず, $400 \mathrm{~nm}^{-1}$ であることが知られている..$^{2 \sim 5)}$ この $M_{\mathrm{L}}$ 值と Table IIに掲げた $M_{\mathrm{v}}$ より見積もられる各試料の経 路長 $L$ Table IIの第4行目に示す.さらにこの $L$ と持続長 $q$ より， Kuhnの統計セグメント数 $N$ を計算することができる.ただし， Table Iに示したように，qは水溶液のイオン強度に依存する. レオロジー測定を行った無塩系では, ヒアルロン酸ナトリウ ム自身のみがイオン強度に寄与する.ヒアルロン酸はモノ マー単位当り 1 個の解離基を有しており, これが低分子塩と 同じように溶液のイオン強度Iに寄与すると見なすと, 次式よ り各高分子質量濃度 $c\left(\mathrm{~g} / \mathrm{cm}^{3}\right)$ におけるIを計算できる.

$$
I=1000 c / M_{0}
$$

ここで, $M_{0}$ はヒアルロン酸ナトリウムのモノマー分子量 $(=$ 401)で，Iは体積モル濃度 (M) の単位で表すものとし , ナト リウム塩型のヒアルロン酸は完全解離しているとした.

Table II 第5 行目以降には, いくつかの高分子濃度の無塩 水溶液中における各測定試料のNの值を掲げてある.計算に は, 式(7)より求めたIにおける $q$ の值をTable Iに示した文献值 を内挿して求めて用いた.ただし，レオロジー測定温度 $\left(35^{\circ} \mathrm{C}\right)$ と文献值の温度 $\left(25^{\circ} \mathrm{C}\right)$ の違いは無視した。

\section{4. 結果と考察}

ヒアルロン酸ナトリウム 4 試料に対するゼロずり粘度 $\eta_{0}$ 対 高分子質量濃度 $c$ の両対数プロットをFig.1中の丸印および四 角印で示す.いずれの試料についても ,データ点は下に凸の曲 線に従っており，高濃度領域での曲線の傾きはいずれも約 3.8 であった.また，Fig.1に示したデータから，適当に選んだいく つかの濃度における $\eta_{0}$ を分子量に対して両対数プロットした 結果をFig.2の丸印および四角印で示す.濃度が $0.001 \mathrm{~g} / \mathrm{cm}^{3}$ にお けるデータ点 (白四角) は傾きが 1.2 の直線に, また濃度が $0.05 \mathrm{~g} / \mathrm{cm}^{3}$ のデータ点 (黑丸) は傾きが $3.6 の$ 直線にほぼ従っ ている.後者は,からみ合い相互作用の働いた屈曲性高分子の 濃厚系に期待される分子量依存性に近い.ただし，中間的な濃 度 $0.01 \mathrm{~g} / \mathrm{cm}^{3}$ のデータ点が，傾き4近くの直線に従っているよ うに見える.同樣な粘度の強い分子量依存性は，すでに Fouissacら ${ }^{2)}$ によって同じ高分子濃度の(ただし，0.1 M NaCl を含んだ）ヒアルロン酸水溶液において報告されている.

Fig.1と2に示した実験結果を，第2節で述べたファジー円筒 モデルに基づく理論と比較する.理論計算に必要なファジー 円筒の有効な長さ $L_{\mathrm{e}}$ と太さ $d_{\mathrm{e}}$ の見積もりには,$q$ と $B$ を知る必 要がある (式(1)〜 (3)参照). 各高分子濃度でのイオン強度は 式(7)より計算され, 各イオン強度での $q$ と $B$ は, Table Iに示し た文献值を内挿することにより求めることができる，ただ し , $c<0.002 \mathrm{~g} / \mathrm{cm}^{3}$ でのIは0.005 Mより小さくなるが , $I<0.005$ $\mathrm{M}$ での $q$ と $B$ の文献值がないため , この濃度領域での $\eta_{0}$ の計算 は行えなかった.また, 式(4)中の固有粘度 $[\eta]$ もイオン強度す なわち高分子濃度に依存するが , この值も式(7)より計算され たIにおける $[\eta]$ を文献值占を頼りに見積もることができる.

理論中に含まれる唯一の未知パラメータは, 式(6)中の $V_{\mathrm{ex}}{ }^{*}$ に含まれる臨界空孔とファジー円筒との相似比 $\lambda^{*}$ である.い まこの值として 0.07 を選ぶと，Fig.1中の実線で示した理論曲 線が得られる.低分子量の 2 試料に対する $\eta_{0}$ の実験結果は理論 線にほぼ従っており，ヒアルロン酸ナトリウム水溶液の粘度 挙動がこの分子量においてはファジー円筒に基づく理論に

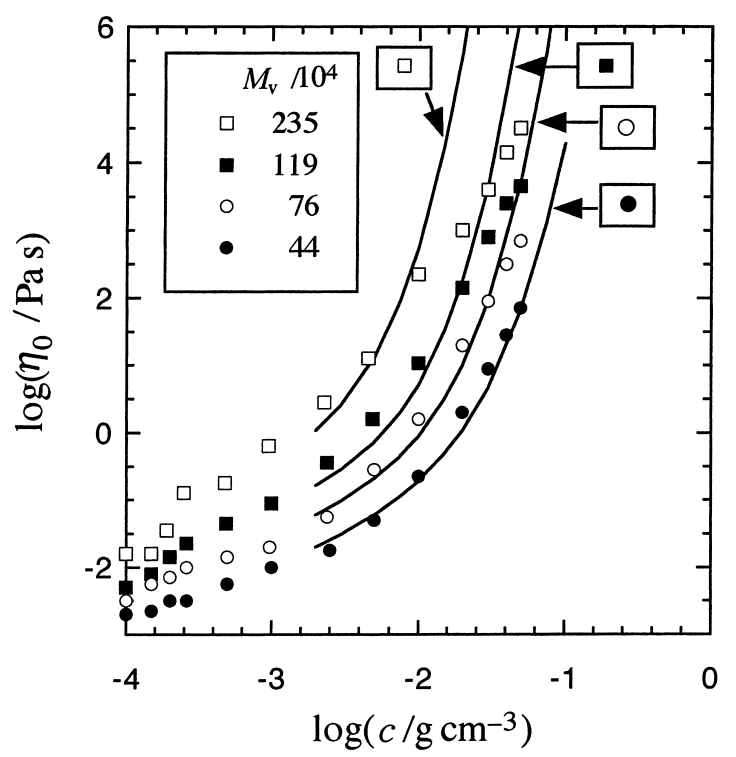

Fig.1 Concentration dependence of the zero-shear visocsity of aqueous solutions of sodium hyarulonate; solid curves, theoretical curves calculated by the fuzzy-cylinder model theory. 


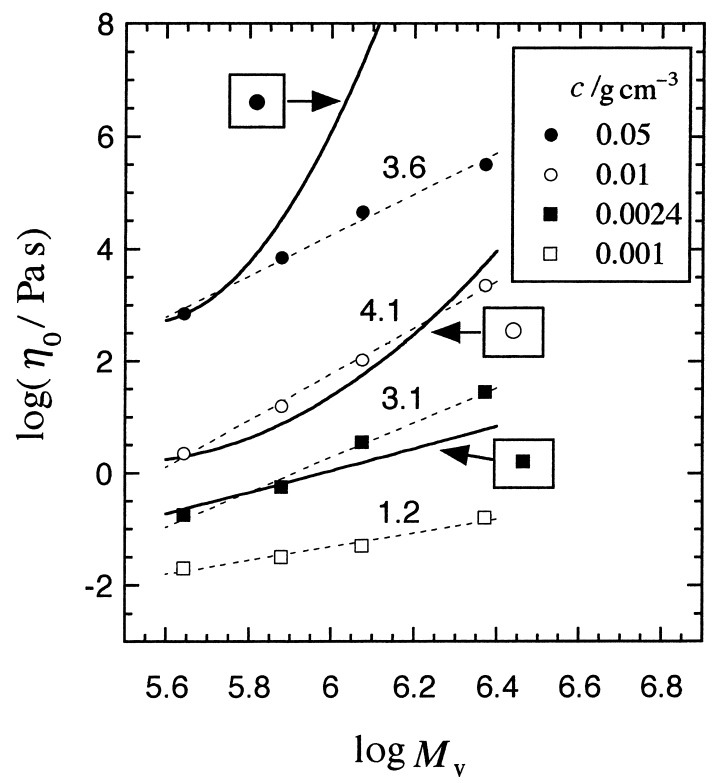

Fig.2 Molecular-weight dependence of the zero-shear visocsity of aqueous solutions of sodium hyarulonate; solid curves, theoretical curves calculated by the fuzzy-cylinder model theory.

よって説明できることを示している.選んだれ゙の值は ,これま でに研究された剛直・半屈曲性高分子溶液系で得られている 值 $(0.03 \sim 0.12)^{6.8}$ の中間に位置している.

Fig.1において, 高分子量2試料に対する理論線は, 実験值 を低濃度側では過小評価し，他方高濃度側では過大評価する 傾向にある.以前に研究された ポリ $n$-ヘキシルイソシアナー 卜) $(q=21 \mathrm{~nm})$ のジクロロメタン溶液の $\eta_{0}$ にいても , 分 子量が非常に高いときには,やはり同樣なファジー円筒モデ ル理論とのずれが見い出されている. ${ }^{11}$ Table IIからわかるよ うに, 高分子量のヒアルロン酸2試料 (DHAS1 と2) のKuhn 統計セグメント数 $N$ は150を超えており，これらのヒアルロン 酸分子はむしろガウス鎖と見なし, 屈曲性高分子系に対する 理論体系 (レプテーションモデル等) に基づいて議論される べきかも知れない、ただし，ここでは屈曲性高分子系に対す る理論による解析は行わない.

Fig.2においても，実線はファジー円筒モデル理論による理 論線であり，高分子量側で実験データ点とのずれか認められ

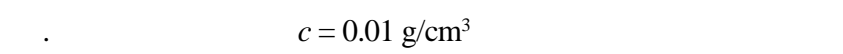
致がかり良いように見えるが, これはFig.1において, 理論 線か実験データをちょうど交差する濃度に対応するためで，
この特別な濃度において理論の妥当性を示しているわけで はない.

\section{5. 結 論}

生体系において重要な役割を持つヒアルロン酸水溶液の ゼロずり粘度を, 半屈曲性高分子溶液に対する代表的な理論 である,ファジー円筒モデルに基づく理論と比較した.分子量 が100万未満のヒアルロン酸試料については, 溶液粘度挙動 が同理論によって，ほぼ定量的に説明され，理論の妥当性が 示された.これに対して, 分子量が100万を超えるヒアルロン 酸試料の水溶液粘度は, この理論では説明できず，理論で無 視されているレプテーション運動のような屈曲性高分子に 特有なダイナミックスが重要になることを示唆している.

謝辞

ヒアルロン酸試料の固有粘度測定に協力していただいた， 大阪大学の中江圭介氏に感謝する.なお, 本研究は, 2001 年3 月 5 日開催の関西レオロジー研究会第19回関西地区修士発表 会における発表と議論を発端にして行われた。

\section{参考文献}

1) Lapcik L Jr, Lapcik L, Smedt S D, Demeester J, Chabrecek P, Chem Rev, 98, 2663 (1998).

2) Fouissac E, Milas M, Rinaudo M, Macromolecules, 26, 6945 (1993), and references therein.

3) Hayashi K, Tsutsumi K, Nakajima F, Norisuye T, Teramoto A, Macromolecules, 28, 3824 (1995).

4) Hayashi K, Tsutsumi K, Norisuye T, Teramoto A, Polym J, 28, 922 (1996).

5) Tsutsumi K, Norisuye T, Polym J, 30, 345 (1998).

6) Sato T, Teramoto A, Adv Polym Sci, 126, 85 (1996).

7) Norisuye T, Fujita H, Polym J, 14, 143 (1982).

8) 佐藤尚弘, 日本レオロジー学会誌, 27, 205 (1999).

9) Yamakawa H, "Helical Wormlike Chains in Polymer Solutions," Springer, Berlin \& Heidelberg (1997).

10) Yamamoto $S$, Takigawa $T$, Masuda $T$, in preparation.

11) Sato T, Ohshima A, and Teramoto A, Macromolecules, 31, 3094 (1998). 